COMMENT

Check for updates

https://doi.org/10.1057/s41599-020-0487-3

\title{
OPEN
}

\section{Designing inter-regional engagement to inform cohesive policy making}

Robin Fears ${ }^{1 凶}$, Claudia Canales Holzeis ${ }^{2} \&$ Volker ter Meulen ${ }^{1}$

\section{ABSTRACT}

The scientific advice needed to inform national and regional policies addressing the key challenges we face today must take account of disparate requirements. The complex nature of the problems addressed in this article-which encompass food and nutrition security, global health and climate change-and the multitude of their interconnections, calls for an integrated and multi-disciplinary approach that spans aspects related to the use of natural resources; the adoption of new technologies all the way to issues related to food demand and human behaviour. The scale is also important: national policies need to respond to a set of heterogeneous local conditions and requirements and should be particularly mindful of the effect on vulnerable groups of the population. At the same time, the global interconnectedness of food systems and shared natural resources also necessitates coordinated action at regional and global levels. The InterAcademy Partnership sought to develop an innovative model for integrating and analysing multidisciplinary scientific evidence to inform governments and regional policy bodies for policymaking on food and nutrition security. This approach relies on IAP's membership of over 130 science academies grouped in four regional networks for Africa, America, Asia and Europe. Our article reviews the model, in particular with regards to interdisciplinarity, exploring examples relating to yield gap, plant breeding and food processing, and reflects on lessons learned during the project discussions and when engaging with policy-makers and other stakeholders. We propose that the framework developed can be applied to integrated assessment of other societal challenges where the scientific community can play a significant role in informing policy choices.

\footnotetext{
${ }^{1}$ The InterAcademy Partnership, Trieste, Italy. ${ }^{2}$ The German National Academy of Sciences Leopoldina, Halle (Saale), Germany. ${ }^{凶}$ email: robin.fears@easac.eu
} 


\section{Introduction}

- he world is experiencing increasing problems, and these are interlinked in complex ways. Attaining food and nutrition security in the face of current demographic challenges and the impact of climate change is a shared priority. According to latest data (FAO et al., 2019), the world is off-track to meet most of the sustainable development goal (SDG) targets linked to food and nutrition security. The number of hungry, undernourished people worldwide has continued to increase during the past 3 years, while health impacts associated with obesity are also rising dramatically. Climate change is expected to have significant and widespread negative impacts on food systems, although there is uncertainty about the scope and scale of such impacts and of potential adaptation responses (Moore et al., 2017; IPCC, 2018). More needs to be done to clarify key econometric issues (Carter et al., 2018), as well as public health issues.

Durable food security is possible (Editorial, 2018) and, of course, science has already made great contributions to agricultural productivity and food quality. Now there must be more attention to tackling demand-side as much as supply-side issues. That is, addressing demand from policymakers for science advice as well as demand for food from consumers. The societal contexts are critically important in understanding and capitalising on the opportunities for science and technology in food systems (Marsden et al., 2018). Action on the demand side, in particular addressing over-consumption and waste, would greatly help to reduce the need for those large increases in food production often assumed (Pastor et al., 2019), with their potentially disastrous impacts on environmental sustainability.

Expertise in social sciences is critical for more nuanced yet robust debates regarding the role and impact of scientific and technical innovations with regards to the problems faced by the most vulnerable segments of the population. One example is the study of yield gaps: the differences between actual agricultural production yield and what is potentially achievable under optimum growing conditions. Often the simplest solution is the use of improved seed varieties and the correct application of fertilisers. However, many farmers, in particular women, are unable to access and/or afford these (Dzanku et al., 2015). Socio-economic barriers to closing the yield gaps are rarely duly considered (Snyder et al., 2017). Asymmetric access to scientific and technological innovations by different parts of the population can in fact increase inequality and poverty (Lefore et al., 2019), highlighting the importance of social justice as a requisite for science to fulfil its role of improving our society.

Science can, and should, inform policy choices (Gluckman, 2014) and provide the resource to drive technical and societal innovation, but these roles require appropriate frameworks for identifying, testing, and using information (Sutherland and Burgman, 2015). Moreover, if innovative interventions are to be successful, there must be more effective communication and dissemination channels between research and policymaking (Editorial, 2019). Various models have been used by scientific bodies in seeking to generate advice that is credible, salient and legitimate (van der Hel and Biermann, 2017), and the Palgrave Communications collection "Scientific Advice to Governments" has provided various perspectives, including a systematic review of how academics might best contribute (Oliver and Cairney, 2019). However, established methods for enhancing accuracy and calibrating expert judgements are rarely used in practice to support public policy decisions (Sutherland and Burgman, 2015), partly because decision-makers must balance a range of political, social, economic, practical and scientific issues, and partly because of continuing uncertainty about the quality and reliability of expert judgements. Moreover, many of the mechanisms for delivering science advice share the weakness of under- representation by the global south (van der Hel and Biermann, 2017). Recent analysis of procedures for delivering science advice to parliaments confirms that the state of evidence is poor in lower-middle income countries (Akerlof et al., 2019) and the highest priority policy domains are in environment and health. Moreover, those who wish to furnish scientific advice must now operate within a changing, more diverse landscape, where stakeholders are participative and less deferential to authority and scientific experts. How should scientists engage in this new landscape? This is the question that we address in this Comment.

We draw on recent and ongoing work of the InterAcademy Partnership (IAP), a global network of more than 130 academies of science, medicine and engineering, bringing together expert networks from Africa, Asia, the Americas and Europe, with the transboundary goal to explore how better to generate and use scientific advice in nutrition, health and other policy areas.

\section{IAP project}

To address some of the challenges, IAP designed an innovative project integrating systematic analysis of evidence and perspectives at national, regional and global levels examining issues for the transformation of food systems to provide healthy, sustainable, diversified, diets amidst climate and other environmental change. The project served also to develop and test a new "ground-up" model for gathering evidence and delivering policy advice which recognises and values diversity. The published regional and global synthesis reports with background on project objectives are available on the IAP website ${ }^{1}$. Many national academies have significant advisory experience at country and regional levels, but others have less of a tradition in this respect and, until recently, there has been little experience of academies working together worldwide. The IAP project facilitated capacity building for academies and their regional networks to generate inclusive and accountable contributions, independent of vested political and commercial interests, supporting engagement between the academies and younger scientists. Because of the leadership roles exercised by academies in the scientific community, IAP is able to draw on the best science, wherever it is found. We agree with the view (Lebel and McLean, 2018) that capacity strengthening and excellence go hand-in-hand. Whatever their tradition or current capacity, academies involved shared in the enthusiasm for this ground-up project committing to the inter-regional spreading of good practice for sustainable food and nutrition security, and the SDG vision "to leave no one behind". By working together, academies can also help to build trust. A recent Wellcome Trust survey ${ }^{2}$ demonstrates that although scientists are trusted by publics worldwide as a source of information, there are regional differences, with lower trust found in Central Africa and South America in particular. Initiatives such as this IAP project may help to raise the level of trust in science worldwide by sharing good practice in collaboration for evidence generation and societal outreach.

In designing the novel initiative, IAP was conscious of the prerequisite to add value to what had already been done by other international, often better-resourced, groups, such as intergovernmental organisations, foundations and public-funded strategic initiatives (for example by the European Commission). A core strength of the project resides in its heterogeneity: utilising diverse experience, expertise and expectations across the regions while, at the same time, conforming to shared academy standards of clear linkage to robust evidence. Project prioritisation of research and policy needs was based on identification of areas and populations with the highest current and future risks for food insecurity. The particular attributes of academies and advantages 
of their worldwide mobilisation have been discussed elsewhere, together with some of the messages emerging from the collective endeavour (Fears et al., 2019; Canales Holzeis et al., 2019a, b).

We now augment those previous analyses by highlighting some of the added value incurred for local-global connectivity across territories and policy areas (Fig. 1), with particular regard to the interdisciplinary linkages across the biosciences and social sciences. Interdisciplinary research is crucial both for project content and process. That is, both to support the identification of scientific priorities and for the effective design of innovative mechanisms to inform the development and implementation of these priorities as policy options. Experience from our project shows that integrating science across disciplines and boundaries helps to strengthen the capacity of systems for (i) increasing the robustness and rigour of the evidence base; (ii) promoting receptivity for the uptake of the outputs from science by policy makers; and (iii) increasingly involving the public in prioritysetting and implementation. It can be difficult to ascertain impact on policy development and its attribution to particular activities within the scientific community but a necessary step to achieving impact is the early and sustained engagement of the scientific and policy communities to exchange information and perspectives. Moreover, recent systematic review (Reynolds et al., 2020) shows that public support for a policy can be increased by communicating evidence of its effectiveness: academies and their networks may also have a significant role here in building capacity to mediate the interaction between policy, practice and public engagement.

The IAP project reports, from Africa, Asia, the Americas and Europe had a dual purpose in policy terms: to stimulate engagement with policy makers at the regional level and to provide resource for the global report and its presentation to policy makers worldwide.

Many of these policy needs are addressed primarily at the country level, including access to health and social support (e.g. affordable food and food banks); others have regional connotations, including redesign of regulatory or market systems (e.g. to reduce waste, increase nutritional quality and diversity of production, tackle land use issues). Some have also to be addressed in an integrated way at the global level (e.g. policies for trade, food safety, development aid, resource use and environmental

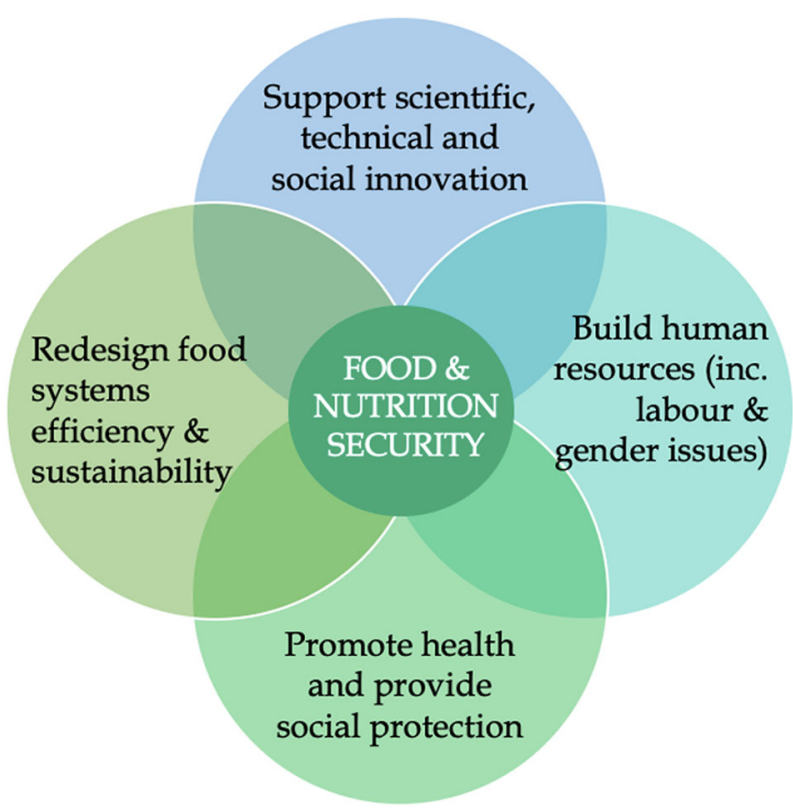

Fig. 1 Policy interrelations for food and nutrition security. sustainability). In those latter cases, global action must be informed and underpinned by national, regional and interregional commitment, aligned with the SDGs (Canales Holzeis et al., 2019b). An integrated view also helps in dealing with synergies, trade-offs and unintended consequences arising from policy disconnects. For example, agricultural policy objectives of intensive livestock or cereal farming to increase food production have negative consequences for policy on greenhouse gas emissions and human health (the rising incidence of obesity and noncommunicable diseases).

There is increasing recognition of the vital importance of defining and providing sustainable diets for human and planetary health. But there is controversy (Canales Holzeis et al., 2019a) on what such diets look like, and recent proposals do not always take into account the relevance of cultural differences and affordability, or sufficiently acknowledge the impact of recent research advances. For example, social sciences research (Fattore and Agostoni, 2016; Marsden et al., 2018) and social practice theory (Sahakian, 2015) are providing new impetus to understanding and influencing consumer and food manufacturer behaviours involved in making dietary choices (e.g. promoting acceptability of nutritious orphan crops) and reducing waste. Food studies can be more engaged in social theory to provide the field with a broader diversity (Neuman, 2019).

One example of the added value obtained by integrating research in the social and biological sciences is provided by an examination of the opportunities emerging for sustainable progress in plant breeding. New scientific opportunities for plant breeding worldwide are coming within range, particularly from advances in genome editing enabling, for example, resistance to biotic and abiotic stresses arising from climate change, playing a significant part in developing climate-sensitive agriculture for both human and planetary health (Fears et al., 2019). A recent survey of bioscientists and social scientists revealed consensus about the enhanced agronomic performance and product quality to be gained for genome edited crops over the alternatives (Lassoued et al., 2019). However, these opportunities cannot be grasped unless there is appropriate flexibility in the regulatory framework proportionately encompassing risk management to encourage innovation. There is concern that an inappropriate emphasis on the precautionary principle inhibits research and development and reduces the number of tools available to enhance agricultural efficiency (EASAC, 2020). A long-standing problem in Europe, that precautionary regulation of genetically modified organisms is not based on scientific evidence and experience, runs the risk of being extended to the newer plant breeding techniques such as genome editing. Policy decisions must take into account scientific advice from across the biosciences and social sciences (Chen et al., 2019) and, also, the lessons of history to identify unintended consequences of policy actions in deterring innovation. The challenge here for plant breeders and scientists, and for employment and competitiveness, might seem to be mainly a European one. However, decisions in one location can create problems from unintended consequences elsewhere, e.g. for those who, hitherto, had looked to Europe for scientific leadership or who (particularly in Africa) desired to export new products to Europe. Trade as a public good requires consistency in embedded regulatory principles to avoid distortion by non-tariff barriers to market access (Canales Holzeis et al., 2019a).

As part of IAP work in this area we have engaged on research priorities for agriculture broadly, with the G20, with national Ministers and other policy makers (in Africa and Europe) with the European Commission (with a view to re-examining options for standard-setting and regulation), and United Nations Economic Commission, as part of regional SDG discussions, and 
with commercial plant breeding companies. We have also involved farmers and the agrochemical sector in the discussion of our outputs, and academy engagement at the global and regional levels has been accompanied by outreach at the country level by national academies of science.

\section{Sustainable food processing and novel foods}

Increasing consumption of processed food evokes health concerns worldwide associated with reduced nutrients and added salt, sugar and fat. Nonetheless, we are optimistic about the potential in food technology opportunities both to produce healthier products and to reconnect with environmental objectives, using green chemistry, biodegradable materials, less water and energy. One contemporary example of a novel food research priority, much discussed in the context of mitigating agriculture's contribution to climate change, is the potential for artificial (cultured) meat. This innovation may become a scalable, land-efficient alternative for animal-source foods, if produced with renewable energy (Parodi et al., 2018). Moreover, the food value of cultured meat could be modified to optimise nutrient content and, as production would not require antibiotic use, it might reduce the spread of antibiotic resistance. However, major changes in food production and consumption associated with various novel food sources have implications for many other policy decisions, including for rural development, human resources and trade, as well as for agricultural and environmental strategies.

IAP follow up on these research and policy options has included engagement with the G20 priorities for global agriculture and the United Nations Economic Commission (to emphasise the implications for climate change) and IAP recommendations have contributed to the long-term strategy for the International Union for Food Science and Technology (IUFoST, 2019). And, to reiterate, IAP activity at the global level is reinforced by regional academy network activity at the regional level and follow-up national academy activity at the local level.

\section{What's next?}

In addition to the specific outcomes and impacts on food and nutrition security, generalisable learning about critical success factors for science advice from this project can be applied to future inter-regional, inter-disciplinary initiatives (Table 1).

Our objective in this novel project design was not to decide between policy possibilities-for that is a responsibility of the political process-but rather, by highlighting the scientific evidence currently available and the information gaps that need to be filled by new interdisciplinary research, to help determine what the possibilities are. It would be fair to say that we in IAP are now at a transition stage from "reaching out" to "connecting for impact". This has implications for future work at all levels. For example, WHO's recent draft health policy Global Strategy document (WHO, 2019) raises the concern that only a limited number of countries have advisory bodies with the mandate or capacity to set the national health research agenda, generate synthesis of available evidence, track national progress on health and the environment, and provide evidence directly to policy makers. In consequence of this and other IAP projects, academies can accrue the science advisory wherewithal to play their part in these national roles.

Although science is central to delivering economic, environmental and societal sustainability it is often still surprising to us how little the voice of interdisciplinary research is heard in many international policy fora. When science is included in debate, it is often derogated to a separate session. The scientific community, including academies, must be even more energetic and tenacious in providing and integrating their expertise. Globally, the IAP report concludes that there would be significant added value in creating an independent advisory panel on the priorities for food and nutrition security, with academy participation in the ensemble, to shape policy options and strengthen governance. Options for creating an international panel on food, nutrition and agriculture, and its roles to support a new international governance platform have been described in detail elsewhere (von Braun

Table 1 Project design features for incorporation into future work.

\section{Strengths of the IAP project design}

Strong core leadership combined with flexibility to build ownership across all regional networks.

Consistency in quality assurance procedures and commitment to peer review.

Collective convening power of academies as an effective tool to facilitate transboundary, multi-disciplinary, inclusive discussion.

Involving younger researchers as well as established experts to build intergenerational connections.

Scholarship proceeds in phases: agreeing a common starting point followed by assessing similarities and differences in the diverse evidence bases, within and between regions, and then synthesis of global messages. Recognition that initial contacts with policy makers must occur early in the project. Involvement of scientists from the global south in contributing advice for regional and global research priorities and policy making.

Emphasis on transparency, e.g. showing where there is consensus on the evidence, where controversial issues need to be clarified and how evidence gaps could be filled.

Significant degree of continuing work to follow up at national, regional and global levels to stimulate debate, test recommendations and incorporate feedback into future work.
Limitations to be overcome

Academies vary in their competencies: hence the importance of the internal project objectives of capacity building and sharing good practice.

There are continuing challenges associated with interdisciplinary collaborations, perhaps particularly between the natural sciences and social sciences and humanities. Some national academies cover only some disciplines but through the academy networks all disciplines can be involved. There is more to be done to capitalise on mutual interests across disciplines and, indeed, a major internal objective of the project is to help inclusive capacity-building. Current IAP projects also seek to involve members of the Global Young Academy as partners.

Not necessarily intuitive to some academies and networks: hence need to learn from this pioneering project. There is also the challenge that there are fewer regional policy clients in Asia and the Americas.

Longer-term impact is difficult to ascertain and so is the attribution of impact to a specific initiative. 
and Birner, 2017; von Braun et al., 2017). The model could partly follow the design of the IPCC although, to be sufficiently flexible, might not have a statutory, intergovernmental basis. The panel would aim to integrate and consolidate the myriad current panels and committees at the international level in this area, to ensure an inclusive, transparent and coherent approach to offering and using research-based evidence.

Received: 20 December 2019; Accepted: 19 March 2020;

Published online: 03 June 2020

\section{Notes}

$1 \mathrm{http}: / / / w w w . i n t e r a c a d e m i e s . o r g / 37646 /$ Food-and-Nutrition-Security-and-Agriculture

2 https://wellcome.ac.uk/reports.wellcome-global-monitor/2018.

\section{References}

Akerlof K, Tyler C, Foxen SE et al. (2019) A collaboratively derived international research agenda on legislative science advice. Palgrave Commun 5:108

Canales Holzeis C, Fears R et al. (2019a) Food systems for delivering nutritious and sustainable diets: perspectives from the global network of science academies. Glob Food Sec 21:72-76

Canales Holzeis C, Fears R, von Braun J, ter Meulen V (2019b) New models for science diplomacy transcending boundries: the interacademy partnership food and nutrition security and agriculture project. Science Diplomacy (05.28.2019)

Editorial (2018) Sustainable agriculture. Nat Sustain 1:531

Editorial (2019) Driving spaceship Earth. Nat Sustain 2:1

Carter C, Cui X, Ghanem D, Merel P (2018) Identifying the economic impacts of climate change on agriculture. Annu Rev Resource Econ 10:361-380

Chen K, Wang Y, Zhang R, Zhang H, Gao C (2019) CRISPR/Cas genome editing and precision plant breeding in agriculture. Annu Revi Plant Biology 70:667-697

Dzanku FM, Jirström M, Marstorp H (2015) Yield gap-based poverty gaps in rural Sub-Saharan Africa. World Dev 67:336-362

EASAC (2020) The regulation of genome-edited plants in the European Union. EASAC

FAO, IFAD, UNICEF, WFP, WHO (2019) The state of food security and nutrition in the world. FAO, IFAD, UNICEF, WFP, WHO

Fattore G, Agostoni C (2016) Health, wellbeing and social sciences. Crit Rev Food Sci Nutr 56:1960-1963

Fears R, Canales C, ter Meulen V, von Braun J (2019) Transforming food systems to deliver healthy, sustainable diets-the view from the world's science academies. Lancet Planet Health 1:e163-e165

Gluckman P (2014) The art of science advice to government. Nature 507:163-165 IPCC (2018) Global warming of $1.5^{\circ} \mathrm{C}$. IPCC

IUFoST (2019) Global challenges and the critical needs of food science and technology. IUFoST

Lassoued R, Maximihano Macall D, Hesseln H et al. (2019) Benefits of genomeedited crops: expert opinion. Transgenic Res 28:247-256

Lebel J, McLean R (2018) A better measure of research from the global south. Nature 559:23-26

Lefore N, Giordano M, Ringler C, Barron J (2019) Sustainable and equitable growth in farmer-led irrigation in sub-Saharan Africa: what will it take? Water Altern $12: 156-168$

Marsden T, Hebinck P, Mathijs E (2018) Rebuilding food systems: embedding assemblages, infrastructures and reflexive governance for food systems in Europe. Food Secur 10:1301-1309
Moore FC, Baldos ULC, Hertel T (2017) Economic impacts of climate change on agriculture: a comparison of process-based and statistical yield models. Environ Res Lett 12:6

Neuman N (2019) On the engagement with social theory in food studies: cultural symbols and social practices. Food Cult Soc 22:78-94

Oliver K, Cairney P (2019) The dos and don'ts of influencing policy: a systematic review of advice to academics. Palgrave Commun 19:21

Parodi A, Leip A, De Boer IJ, Slegers PM, Ziegler F et al. (2018) The potential of future foods for sustainable and healthy diets. Nature Sustain 1:782-789

Pastor AV, Palazzo A, Havlik P, Biemans H, Wada Y, Obersteiner M, Kabat P, Ludwig F (2019) The global nexus of food-trade-water sustaining environmental flows by 2050. Nat Sust 6:499

Reynolds JP, Strautz K, Pilling M, van der Linden S, Marteau TM (2020) Communicating the effectiveness and ineffectiveness of government policies and their impact on public support: a systematic review with meta-analysis. R Soc Open Sci 7. https://doi.org/10.1098/rsos.190522

Sahakian M (2015) Getting emotional: historic and current changes in food consumption practices viewed through the lens of cultural theories. In: Kennedy EH, Cohen MJ \& Krogman N (eds) Putting sustainability into practice. Edward Elgar Publishing

Snyder KA, Miththapala S, Sommer R, Braslow J (2017) The yield gap: closing the gap by widening the approach. Exp Agric 53:445-459

Sutherland WJ, Burgman M (2015) Policy advice: use experts wisely. Nat News 15:526. 317

van der Hel S, Biermann F (2017) The authority of science in sustainability governance: a structured comparison of six science institutions engaged with the Sustainable Development Goals. Environ Sci Policy 77:211-220

von Braun J, Birner R (2017) Designing global governance for agricultural development and food and nutrition security. Rev Dev Econ 21:265-284

von Braun J et al. (2017) Key policy actions for sustainable land use and water use to serve people. Economics 11:1-14

WHO (2019) Global strategy on health, environment and climate change A72/15 WHO

\section{Competing interests}

The authors declare no competing interests.

\section{Additional information}

Correspondence and requests for materials should be addressed to R.F.

Reprints and permission information is available at http://www.nature.com/reprints

Publisher's note Springer Nature remains neutral with regard to jurisdictional claims in published maps and institutional affiliations.

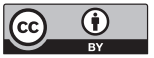

Open Access This article is licensed under a Creative Commons Attribution 4.0 International License, which permits use, sharing, adaptation, distribution and reproduction in any medium or format, as long as you give appropriate credit to the original author(s) and the source, provide a link to the Creative Commons license, and indicate if changes were made. The images or other third party material in this article are included in the article's Creative Commons license, unless indicated otherwise in a credit line to the material. If material is not included in the article's Creative Commons license and your intended use is not permitted by statutory regulation or exceeds the permitted use, you will need to obtain permission directly from the copyright holder. To view a copy of this license, visit http://creativecommons.org/ licenses/by/4.0/

(C) The Author(s) 2020 